Archived version from NCDOCKS Institutional Repository - http://libres.uncg.edu/ir/asu/

Megan Johnson, Andrea Leonard \& John Wiswell (2015) Deciding to Change OpenURL Link Resolvers, Journal of Electronic Resources Librarianship, 27:1, 10-25, DOI: 10.1080/1941126X.2015.999519.

Version of record available from Taylor \& Francis at: http://dx.doi.org/10.1080/1941126X.2015.999519

\title{
DECIDING TO CHANGE OPENURL LINK RESOLVERS
}

\author{
By: Megan Johnson, Andrea Leonard, and John Wiswell
}

\begin{abstract}
:
This article will be of interest to librarians, particularly those in consortia that are evaluating OpenURL link resolvers. This case study contrasts WebBridge (an Innovative Interface product) and LinkSource (EBSCO's product). This study assisted us in the decision-making process of choosing an OpenURL link resolver that was sustainable to maintain and, most importantly, made it easier for users to access the full text of an article. This case study does not propose that one product is superior to another; however, the criteria and methods used to evaluate the products will be of use to those seeking to improve user access.
\end{abstract}

KEYWORDS OpenURL, usability study, LinkSource, WebBridge, consortia 
Deciding to examine and change OpenURL link resolvers is a significant investment in terms of time spent in thorough product evaluation. Foremost in Belk Library's decision making was the desire to improve access for the end-user. This article reports our decision-making process to migrate to a new OpenURL link resolver. In this evaluation, it was important to consider the whole system, both from the end-users' experience with finding resources and from the library personnel's time and effort in the maintenance and troubleshooting of the systems. The two primary measures used were (1) a task-based usability test with end-users and (2) an evaluation by library personnel of the products' backend link setup, maintenance, and control of the menu panels. Appendix A describes the end-user usability test and Appendix $B$ lists the product features for the functional evaluation.

Appalachian State University (ASU) is part of the 17 campus University of North Carolina system. ASU serves 15,712 undergraduates and 1,877 graduate students, and it offers one doctoral program in the College of Education. Belk Library subscribes to nearly 500 research databases.

ASU is part of the Western North Carolina Library Network (WNCLN) consortium with two other universities, the University of North Carolina at Asheville (UNCA), and Western Carolina University (WCU). Belk Library and Information Commons uses Innovative Interfaces' online catalog with the Sierra library system software and EBSCO's A-to-Z e-resources management system, all as part of WNCLN agreements. The consortium has shared Innovative Interface's cataloging platform since 1998.

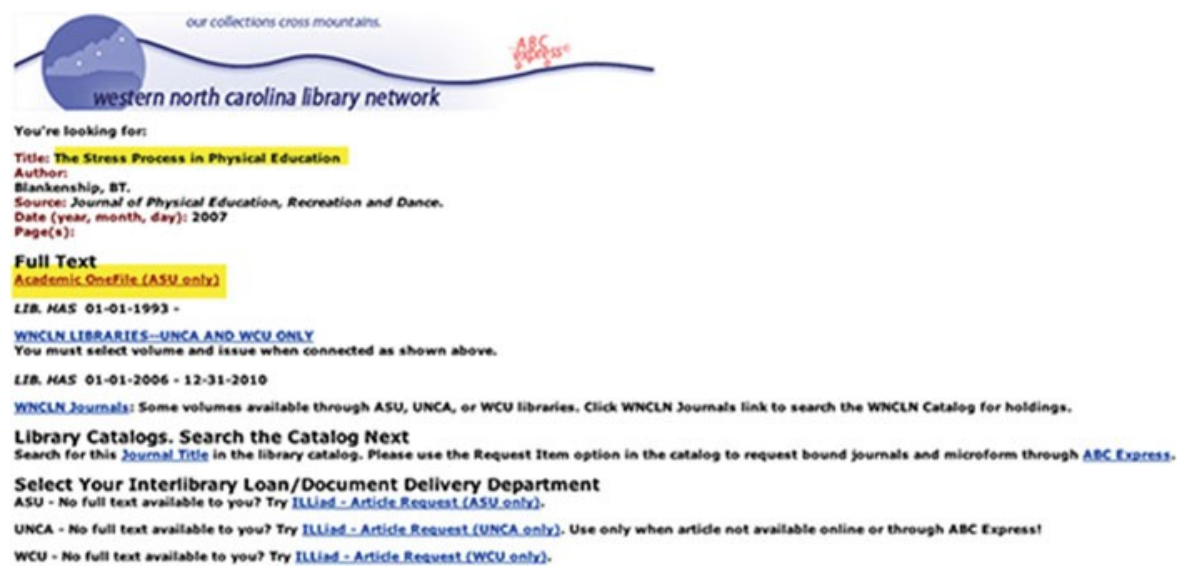

Figure 1 Shared WebBridge Panel.

\section{BACKGROUND}

Belk Library first implemented WebBridge in 2003 as part of a WNCLN consortium wide agreement. WebBridge is a do-it-yourself tool with limited technical support offered by Innovative Interfaces. The WNCLN Systems Administrator set up and maintained WebBridge for all three institutions, and the individual universities had little local control. From 2008 to 2011, the consortium also shared EBSCO's Ato-Z e-journal management system. There were challenges to overcome as each institution tried to manage its subscriptions together in a single administrative interface, such as confusion over coverage dates, which led to inaccurate data and frequent failed OpenURLs. 
Additionally, patrons from all three institutions were presented with an interface menu that offered resources from all three institutions. Depending on budgets and collection management selections of each school, some resources, often many, were not available to all. This was confusing for users. The awkwardness of this "togetherness" as a consortium was evident in the WebBridge menu panel. Patrons got lost in all the text (see Figure 1).

By spring 2011, the WNCLN E-Resources Committee decided that shared e-resources access and management are inherently difficult, if not impossible, among several institutions. The members of the committee proposed as a first step the separation of the shared WebBridge implementation. End-users would then be presented with a clear choice reflecting only their institutions' links in the WebBridge panel (see Figure 2).

To make this change, librarians and staff at each institution learned the details of WebBridge functionality, setup, maintenance, and how to troubleshoot. Maintaining the OpenURL links takes technical knowledge and thorough understanding of how the data are passed between the e-resources databases to WebBridge and then offered in the WebBridge menu panel to the patron.

The administrative interface included all three universities' resource definitions in one administrative module with the same logon. Patrons saw each institution's stand-alone WebBridge in the menu panel, which helped the public interface, but a shared administrative interface was challenging for all three universities.

Unfortunately, some smaller vendors' technical platform could not handle the unique URL syntax required for each institution's separate instance of WebBridge. As a workaround, the WNCLN Network Administrator developed a URL resolution that sent patrons to a menu panel to choose their

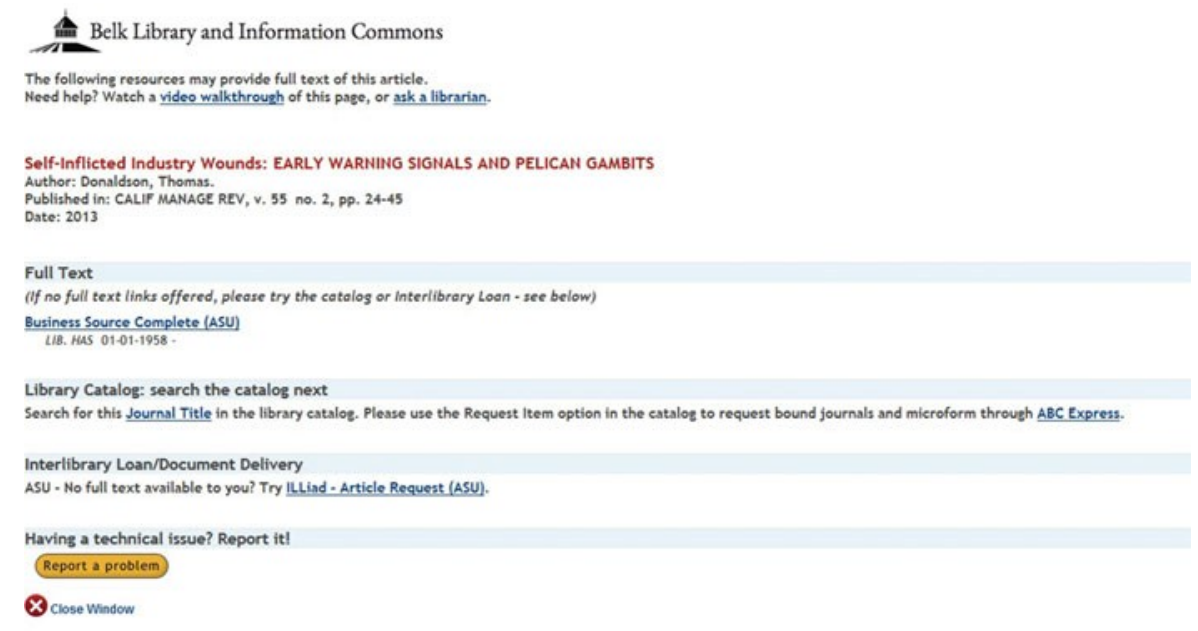

Figure 2 WebBridge Panel with only ASU resources.

institution's affiliation. In usability studies and anecdotal observations, this screen frequently presented itself as a barrier to seamless access. WebBridge does have a feature for connecting to full text via "Direct Connect" that enables click-through access for patrons to articles, bypassing the WebBridge 
menu panel and going straight to the article. The "choose an affiliation" menu panel, however, both broke that direct connection and added an extra step.

In the fall of 2011, the consortium moved from a shared version of EBSCO's A-to-Z to stand-alone instances of EBSCO's A-to-Z for each institution. This made coverage data that were pulled from A-to-Z for the WebBridge coverage files more accurate, which meant fewer error messages and dead ends for patrons. During this move, we determined that LinkSource, EBSCO's OpenURL link resolver, came bundled with A-to- $Z$ and that it could be tested as an alternative alongside WebBridge for an apples-toapples comparison. In spring 2013, we began exploring LinkSource from both the end-user experience and from the maintenance and setup perspective.

\section{LITERATURE REVIEW}

Libraries depend on smooth linking from a users' search to full text. This does not happen by magic, but through a complex system of transactions. Librarians typically discuss the system in terms of link resolver technology coupled with the knowledge bases that allow the technology to work. The knowledge bases include standardized article metadata and library holdings data (Culling, 2007; Glasser, 2012). OpenURL is a protocol of the National Information Standards Organization (NISO) that standardizes metadata (Apps \& Maclntyre, 2006; Stohn, Ewing, Meares, \& Moss, 2011) to make knowledge bases more consistent and easier to build and maintain.

The technology has come a long way since Herbert van de Sompel introduced it in 2000. In 2006, Livingston, Sanford, and Bretthauer remarked that their link resolver's problems were due in part "to the adolescence of the OpenURL standards and linking technology" (p.180). By 2012, Marshall Breeding noted the maturity of these technologies, "with each of the key commercial products having ample time to match the features and functionality of its competitors" (2012a, p.175).

Breeding (2012) reviewed the major link resolvers and their associated e-resource knowledge bases. He reported that EBSCO's LinkSource and Integrated Knowledge Base was one of the best products, comparable with Ex Libris and Serials Solutions products, and superior to a "second tier" of products that included WebBridge. Innovative's WebBridge does not have its own knowledge base; it uses OCLC's WorldCat Knowledge Base or other coverage files downloaded from knowledge bases such as EBSCO's A-to-Z, as was the case at Belk Library.

Glasser (2012) describes KBART (Knowledge Bases and Related Tools) and IOTA (Improving OpenURLs Through Analytics) that have provided more consistent user access to full text. KBART and IOTA both address best practices for and standardization of components of OpenURL. KBART focuses on the quality and consistency of library holdings data, while IOTA focuses on standardization of article URLs, so link resolvers can process them accurately. IOTA analytics quantify content-provider performance. Poor overall performance results in a poor score that is visible to everyone, but IOTA also measures which URL components are failing, so content providers can address them.

In addition to the link resolving software, the standardized URLs, and the library holdings databases, there is one more important component to the system for delivering users to the full text content of 
articles. This component is the user interface. O'Neill (2009) and Imler and Eichelberger (2011) analyzed the user experience with their libraries' link resolvers and asked if the interfaces might be better designed. When users are given a complex menu of choices, they are understandably confused. This is true even when the links are intended to be helpful, such as information about print-journal holdings. Highsmith and Ponsford (2011) and Ponsford, Stephens, and Sewell (2011) discussed redesign of their link-resolver interface at Texas A\&M. They emphasized that results showed that users expect to find the full text and nothing else. They improved the interface but did not reduce the complexity as much as their conclusions suggested that users desired.

Trainor and Price (2010) described their work in improving the link-resolver interface at Eastern Kentucky University. They simplified the interfaces for end-user needs and used data analysis of failures to fix common linking problems. The improved interface still included links to report problems, to get help from library staff, and to search Google Scholar.

Pesch (2012) discussed OpenURL linking in 2012. IOTA analysis showed that OpenURL quality was high. In one large test, $96 \%$ of the OpenURLs were successful. Pesch then turned his attention to user expectations and how librarians can respond. He noted that users expect full text with every link. Pesch suggested that libraries could load holdings of online journals and holdings of physical journals. Then, instead of complex interfaces, users can then be presented with a single, simple message that manages their expectations: "Click for full text," "Click to check library's print collection," or request an interlibrary loan (p.144).

\section{TESTING TIMELINE}

Early in spring semester 2013, we planned a strategy for testing and comparing WebBridge and LinkSource. The plan was broken into these stages: planning and setup, usability testing of WebBridge, usability testing of LinkSource, maintenance and functional comparison of both, discussion of outcomes, and the final decision.

In February of 2013, EBSCO set up LinkSource in A-to-Z, so that we could add the LinkSource URL in two of Belk Library's smaller vendor databases as test beds. Since the WebBridge and LinkSource testing would have to be "live," the choice for the two testing databases were International Medieval Bibliography and MathSciNet. This selection was based on two factors: low usage databases and frequent citation-only search results, which resulted in end-users being presented with the "Choose Affiliation" menu for WebBridge. If LinkSource could handle these smaller vendor databases smoothly, it would not only eliminate the need for the extra step of the "Choose Affiliation" screen, it would connect the patron directly to the article, which would be a vast improvement. Like WebBridge's "Direct Connect" to articles, EBSCO's LinkSource refers to its version of this feature as "direct link to full text." For the purposes of this article, we will use the generic term "unmediated link to full text."

During the spring and summer of 2013, we performed maintenance and functional comparisons using both International Medieval Bibliography and MathSciNet. In the summer of 2013, the usability study of WebBridge was performed using the International Medieval Bibliography database. After changes were made, the usability study was repeated with LinkSource in late 2013.

\section{USABILITY STUDY METHODOLOGY AND RESULTS}


The purpose of the usability study was to benchmark user satisfaction with the OpenURL interfaces and the users' ability to navigate them. As mentioned above, the decision to study user behavior with OpenURL link resolvers was prompted by anecdotal observation and usability studies that the library had previously conducted. Appendix A contains the script and notes for the study.

This was a brief task-based study, where subjects used a relatively obscure database to search for two articles. WebBridge was tested first in the summer of 2013, and then, after changes were made, LinkSource was tested in late 2013. In both cases, testing was conducted with nine representative endusers: three undergraduates, three graduate students, and three faculty members. Several sources state variations on the perfect number of participants in a usability study, but, generally, "For diagnostic usability testing, six to eight users are usually enough to uncover the major problems" (Usability.gov, 2015).

\section{Task 1}

- Subjects were asked to find the article title owned by the library: "The Sword Hrunting in Beowulf: Unlocking the Word Hord."

- Success was defined as the subject navigating from the WebBridge panel to the article

- without coaching.

- Failure was defined as the subject giving up, expressing frustration, or exceeding 2 minutes of searching for the next step.

\section{Task 2}

- Subjects were asked to search for an article not owned by the library: "The Symbolic Meaning of the Scabbard Decoration of the Reich Sword."

- Success was defined as the subject navigating the WebBridge or LinkSource resolution panel and choosing Interlibrary Loan as the option.

- Failure was defined as subject giving up, expressing frustration, or exceeding 2 minutes of searching for the next step. 


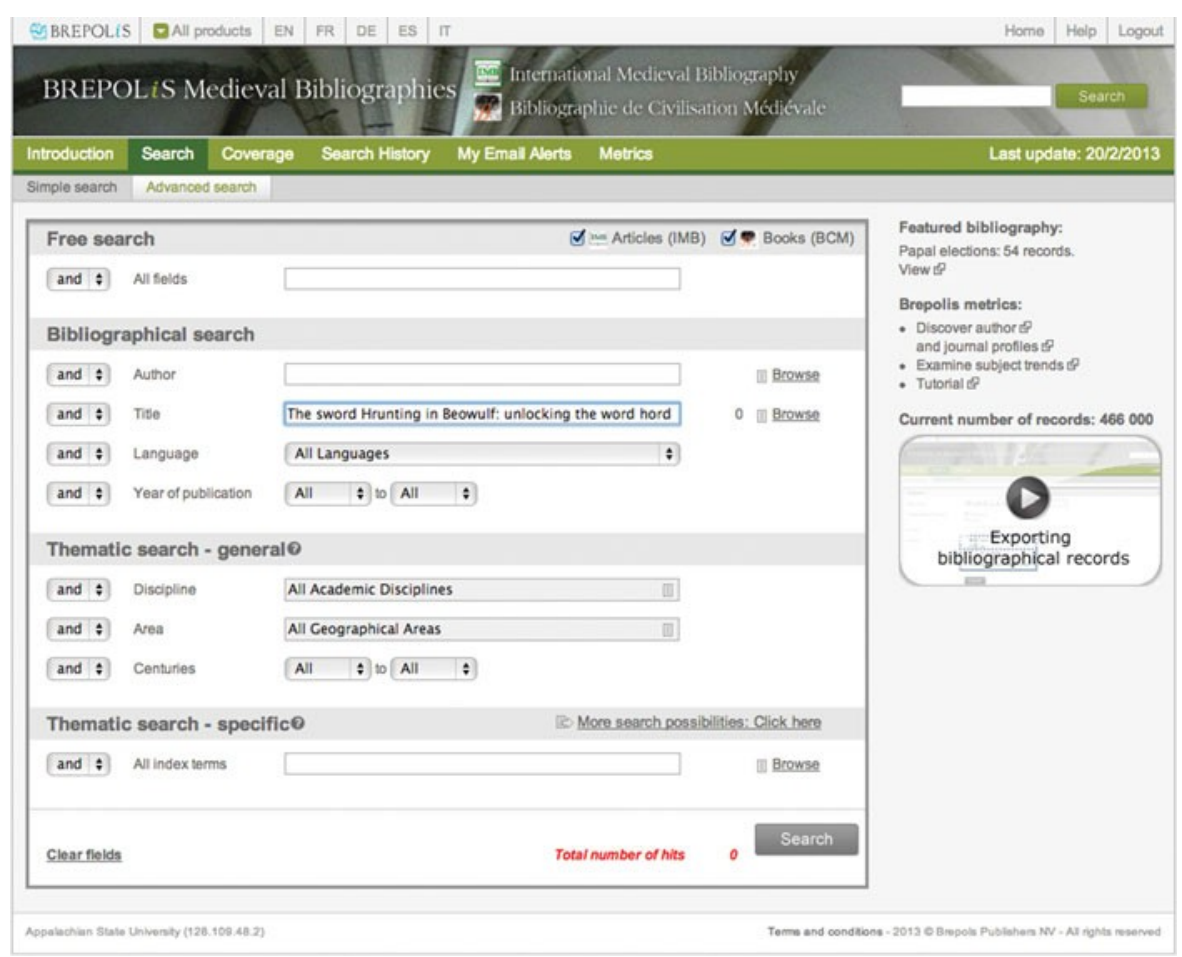

Figure 3 Advanced search screen of test database, Task 12013

\section{WebBridge Task 1}

Subjects were directed to start at the database's advanced search screen. They were given the article titles to copy and paste into the title field (see Figure 3).

Subjects were prompted to use the gold "Find@ASU" button as seen on the right in Figure 4.

The WebBridge panel appeared (see Figure 5), which was the subject of the actual usability study. The subjects were no longer coached.

After the subjects chose affiliation, the next screen (see Figure 6) presented a choice of databases where the article appeared.

\section{WebBridge Task 1-Results}

Part of the reason for including task 1 in the study was to confirm and document that the "average user" often found this panel confusing. Previous usability tests and anecdotal experience had indicated that this panel was a stumbling block for many users. The results were a little surprising, in that eight of the nine participants were successful in navigating this screen. One undergraduate totally failed and had no 


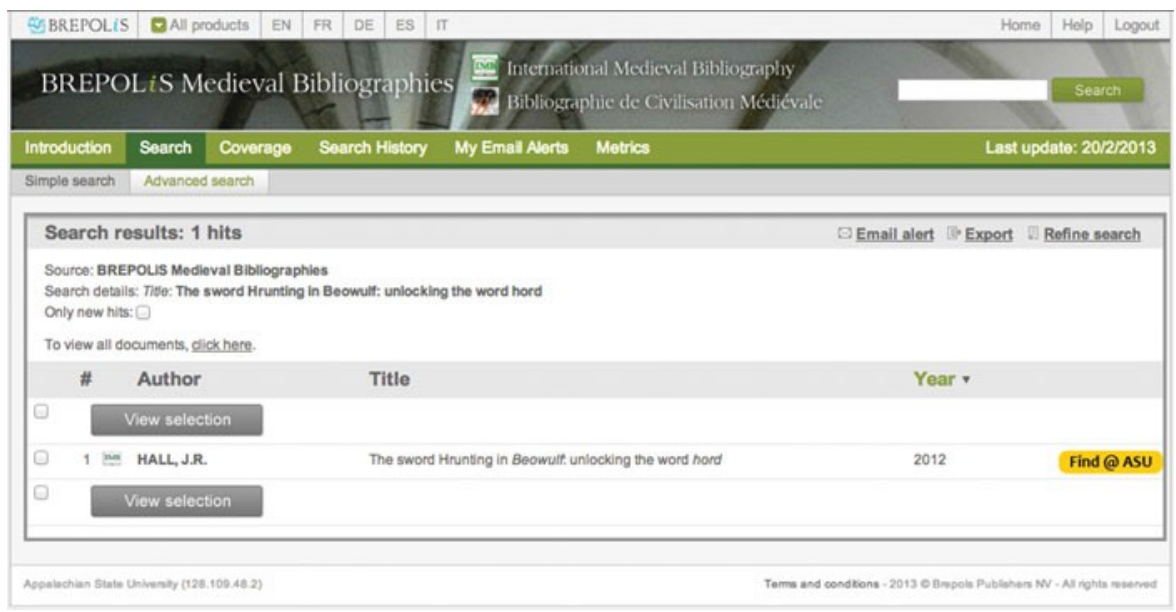

Figure 4 Task 1 showing "Find@ASU” button.

idea what to do. Of the eight who were successful, one of the graduate students took about 20 seconds to choose affiliation, which is a little long for a task that should not be a barrier. In doing usability studies, there is also a chance that the user is behaving slightly differently because they know they are being observed (UEPA [User Experience Professionals' Association], 2012). It could be that subjects are more persistent in searching because they were being watched.

As mentioned above, one subject did not get as far as the screen pictured in Figure 6. For the other eight, almost all paused for quite some time. Several subjects were obviously confused about where to click. All eventually clicked on the first link for Academic Search Complete, which led them directly to the article. Technically, eight of the nine users were successful in Task 1.

\section{WebBridge Task 2}

For the second task, the user was prompted to return to the advanced search screen of the database, International Medieval Bibliography, and copy and paste the second article title "The Symbolic Meaning of the Scabbard Decoration of the Reich Sword," which the library does not own. Subjects were then

Western North Carolina Library Network

The sword Hrunting in Beowulf: unlocking the word hord

Author: HALL, J.R.

Published in: Studies in Philology, v. 109 no. 1, pp. 1.18

Date: 2012

For access to resources that might be available through your institution, select a university affiliation and choose "Submit": Drop Down ASU S SUBMIT

Х Close $n$ Select Affiliation

ANCA

UNCA
WCU

Figure 5 Task 1 "choose affiliation" screen. 


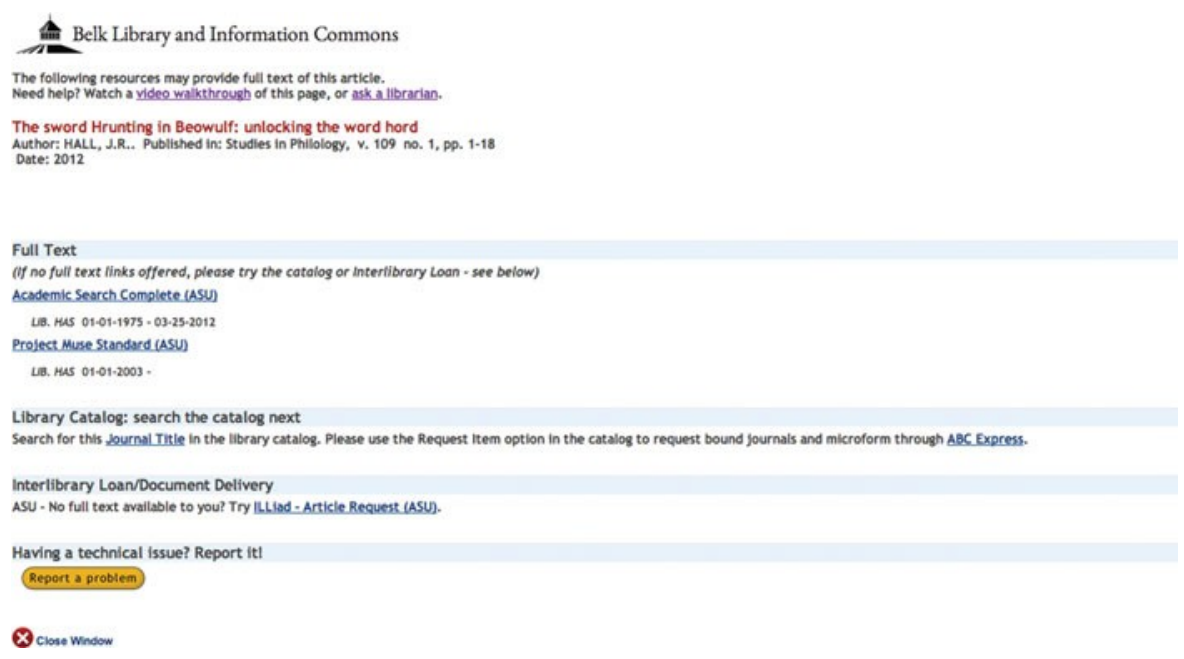

Figure 6 WebBridge result for first article 2013.

prompted to click on the yellow "Find@ASU" button. The subject who did not succeed at the "Choosing Affiliation" screen in Task 1 was coached during Task 2.

Figure 7 shows the WebBridge panel subjects encountered. The "successful" solution for the user in this case would be to order the item through Interlibrary Loan/Document Delivery, which is the third option offered.

\section{WebBridge Task 2-Results}

When users clicked to the screen pictured in Figure 7, all nine subjects clicked on the first available link, "search for this journal title," which brought them to the screen shown in Figure 8 which shows the results from the library's catalog of journal holdings.

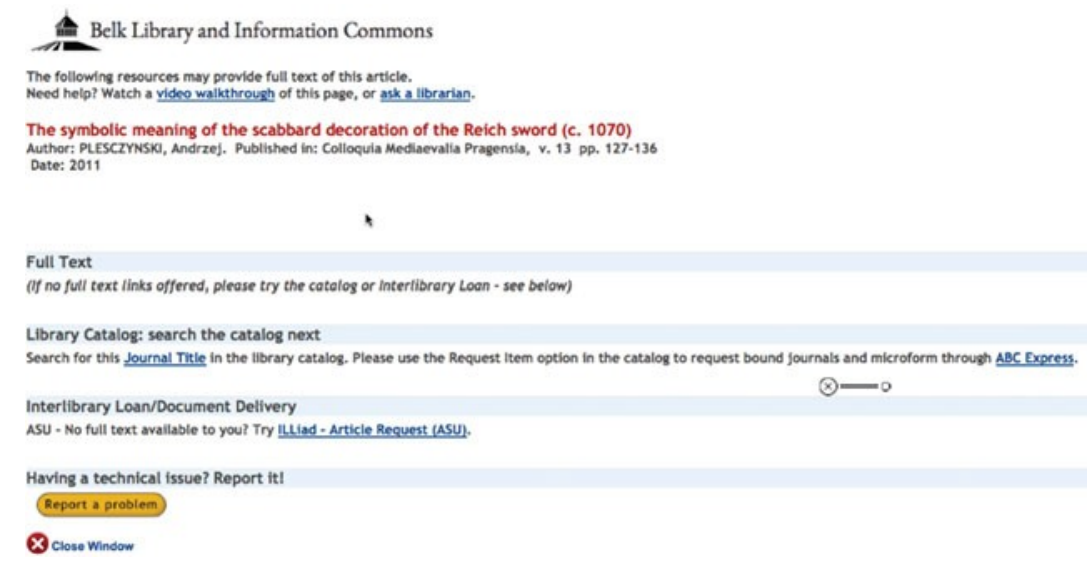

Figure 7 Task 2 WebBridge panel of an article not owned by library 2013. 


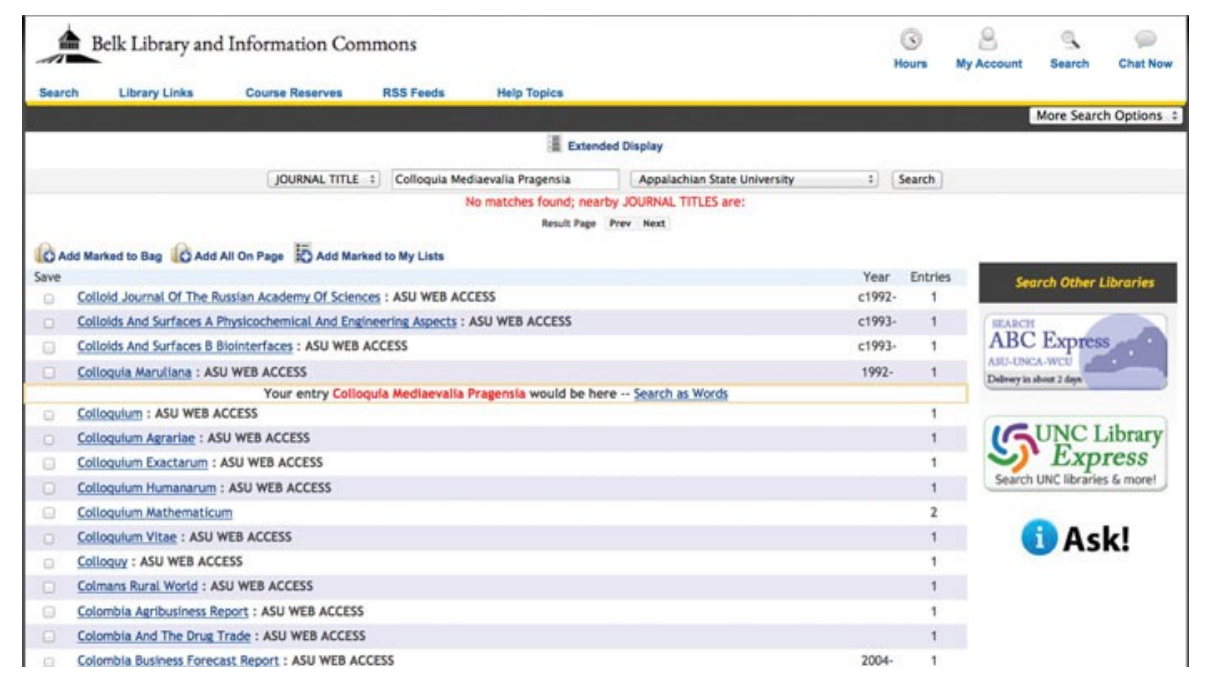

Figure 8 A list of journal titles in the OPAC.

All nine users appeared confused by this screen. Admittedly, the journal title, Colloquia Mediaevilia Pragensia is not instantly recognizable as a common journal title; however, subjects probably did not read all the text around the link saying, "search for this journal title in the library catalog" as shown in Figure 7. Only three of the nine subjects went back to the WebBridge panel pictured in Figure 7 and reached the link for interlibrary loan. This indicates that users were indeed confused by being led to search for a journal title the library does not own in print.

We were curious to see if any users clicked any of the links for help at the top of the page pictured in Figure 7: a video, an "ask a librarian" link, or the "report a problem" link. None of the nine subjects used these tools. This was a small group, but it does indicate that users do not want a complicated set of instructions. They just want to get to the full text of an article.

\section{USABILITY TESTING FOR LINKSOURCE}

\section{LinkSource-Task 1}

After LinkSource was fully implemented, a repeat of the usability studies was conducted in late 2013. For the second round of the usability study, the population was again randomly recruited; three faculty members, three graduate students, and three undergraduates.

\section{LinkSource-Task 1-Results}

All nine were successful getting through the first task, since the URL link to the first article was now an unmediated link to full text of the article. Users no longer encountered a menu. Access had clearly improved. 


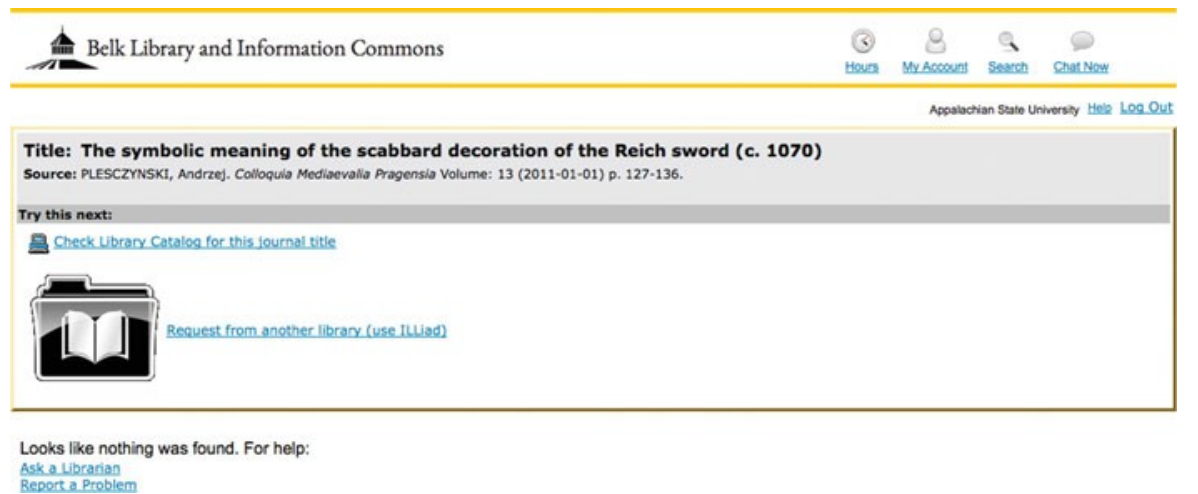

Figure 9 LinkSource Interlibrary Loan Request Screen 2013.

\section{LinkSource-Task 2}

For the second task, the subject was prompted to return to the advanced search screen of the database, International Medieval Bibliography, and copy and paste the second article title "The Symbolic Meaning of the Scabbard Decoration of the Reich Sword," which the library does not own (see Figure 9).

\section{LinkSource-Task 2-Results}

In testing LinkSource for Task 2, the undergraduates and the graduate students all clicked directly to the "request from another library" icon, perhaps simply because the icons imply "take action" to these users. All were successful in getting to the interlibrary loan request screen.

The three faculty members all clicked on the text link first for "check library catalog for this journal title." They appeared to be going through the screen in a more linear fashion, rather than jumping to an icon. Once again, this is too small a sample set from which to draw conclusions. The journal-holdings screen (pictured in Figure 8) confused two of the faculty members. One never reached the interlibrary loan screen. Overall, eight of nine subjects were successful in the second task, a vast improvement in the users' experience over using the previous link resolver.

It is clear from these tests that the LinkSource menu with an icon is more usable for the student subjects in this sample rather than the WebBridge panel, where only three subjects completed Task 2 successfully. It is clear, however, that further improvements can be made to provide better service, and further usability tests can help inform decisions.

\section{EVALUATION OF MAINTENANCE FUNCTIONALITY}

The second component of this case study was the setup of resources and the backend maintenance for WebBridge compared with LinkSource. To do this, we compiled a table with 12 functions and features to evaluate. Appendix B summarizes our evaluation criteria. The three crucial features for Belk Library were the direct-linking functionality, the ease of setting up and maintaining the OpenURL resources, and the level of technical support available. Other important elements included control of the patron menu interface, ability to rank and delete resources, management of the coverage files, performance of data 
tests, Interlibrary Loan functionality, library catalog functionality, user-friendliness of the administrative interface, and functionality of Google Scholar and PubMed. Three crucial features are highlighted in the following paragraphs.

In the usability study outlined in the previous section, unmediated access without having to go through a menu panel with choices to make was considered the ultimate success. Questions spanning the decade that WNCLN used WebBridge revolved around how many databases to activate as direct connects and how often patrons were sent to a dead-end.

Innovative's direct connect feature allows the setup of multiple resources the library chooses. Historically, the library had set up only those databases that were stable and reliable, such as JSTOR, ScienceDirect, and SpringerLink, some becoming steadily more consistent in behavior as the OpenURL standard matured. There is an inherent advantage to WebBridge in having flexibility with Direct Connect, as it gives the library the ability to offer only databases that reliably resolve. When we found out that EBSCO's LinkSource's direct link to full text feature was all or nothing (in other words, it was not possible to select only stable databases as direct link to full text), there was concern that this might create a decision point to stay with WebBridge. This concern, however, was unfounded.

LinkSource has proven to be reliable. The few times that a LinkSource direct link to full text has failed has been much lower than the unavoidable encounter with WebBridge's "Choose Affiliation" menu for the smaller vendor databases. In fact, known problems with LinkSource connections have been the typical problems of all OpenURL link resolvers: dissertations, small publishers whose metadata takes patrons to the journal title level, or inaccurate metadata. All things considered, LinkSource has created a much better experience for Belk Library's patrons, with its unmediated linking to full-text function.

One of the test databases was MathSciNet and, based on an initial review of WebBridge statistics from the fall semester 2012 (approximately 19 clicks) versus LinkSource statistics (32 clicks) from the fall semester 2013, use of the Find@ASU button has nearly doubled since the move to LinkSource. While deeper analysis would need to be performed for an accurate assessment, these initial numbers are encouraging.

WebBridge requires a deep understanding of how link resolvers work, the syntax of the OpenURL links, and how those links communicate metadata. Setting up link syntax was often a complex and tedious task that required testing and tweaking until it worked. In fact, we used a flowchart to ensure that no steps were omitted, relied on advice from the WNCLN network librarian, and often referred to the WebBridge wiki and listserv for help in trouble shooting problems. Statistics were difficult to tease out among the three institutions, as the data were not separated. The administrative interface lacked basic, expected functionality, such as returning to the very top of a long list of resources after editing one, rather than taking a user back to where he or she began an edit. This made maintaining resources even more tedious. The knowledge acquired, however, was valuable and transferable in helping us set up, evaluate, and troubleshoot LinkSource functions.

Technical support was a crucial, if not the most important, factor to consider. Belk Library strives to avoid key-person dependency so that access to resources is as consistent as possible. The setup and maintenance of WebBridge takes solid technical knowledge, much like being able to service your own automobile. There are multiple details to juggle, such as figuring out the link syntax for full-text databases, performing data tests to target specific elements in the metadata when links are not 
working, formatting data to try to standardize the communication between the databases, and setting up citation databases serving as starting points for patrons.

Innovative does provide documentation, a listserv, and a wiki for its customers to share solutions, all of which are helpful. However, it does not provide technical personnel to fix problems or even to offer advice. The amount of time we spent began to seem unreasonable once LinkSource became a viable option. EBSCO offers a wide range of levels of technical support for LinkSource, from completely setting it up and supporting it to allowing complete local control. While there is no listserv or wiki that we are aware of for customers to contribute solutions, EBSCO's documentation is helpful.

See Appendix B for descriptions of the other features tested, observed, and compared: control of the patron menu interface, ability to rank and delete resources, management of the coverage files, performance of data tests, interlibrary loan functionality, library catalog functionality, user-friendliness of the administrative interface, Google Scholar, and PubMed.

\section{RESULTS DISCUSSION}

After testing during the summer of 2013 and demonstrating the two link resolvers at a library faculty meeting, our colleagues agreed that LinkSource is superior for Belk Library's electronic resources environment. For our patrons, more frequent unmediated access to full-text articles and not having to navigate the WebBridge "Choose Affiliation" menu for small vendor databases has been a dramatic improvement. In addition, the change is invisible to patrons since the Find@ASU button usually now connects directly to full text. A menu panel rarely appears. Moving to LinkSource has taken Belk Library and Information Commons to a new level toward unmediated access for our patrons.

For library staff, the ease of setup and maintenance of LinkSource has noticeably reduced the amount of time spent on troubleshooting the complex details of WebBridge. We are also no longer key-person dependent, as EBSCO will perform all tasks related to LinkSource for us if needed.

\section{CONCLUSIONS}

The library is further investigating presenting the link to the catalog for print holdings only when necessary. To do this, the library will try uploading our print holdings to EBSCO A-to-Z, although inconsistent metadata may be an obstacle.

Currently, if the full text does not appear, the patron is still presented with two links: one to check the catalog and one for interlibrary loan. Pesch (2012) recommends a simpler path for items not available immediately electronically. If owned in print, the catalog opens to the journal holdings page. If the library has neither electronic nor print, the patron is offered interlibrary loan.

To further improve service, the authors will recommend that Belk Library move to full document delivery for items not owned electronically. Patrons would see an option for "get it for me." If the patron requests we get it for them, the library would retrieve the article for the user, regardless of its 
location; if owned in print, the item would be scanned and sent via e-mail; if not owned, the item can be acquired through interlibrary loan.

The process of comparing WebBridge and LinkSource illustrated the complexity of consortia management. Link resolvers and A-to-Z journal-management systems are less complicated for the user and the library staff when set up separately for each institution. Since the consortium started more than 20 years ago, patrons' methods of accessing information have changed radically. The consortium is still valuable for sharing the integrated library system, print materials, and access to large e-book packages, but its purpose continues to evolve.

Other steps to investigate are elegantly provided in Trainer and Price (2010, pp. 24-25). The goals relevant to Belk Library are based on their Top Ten List of Tasks to Improve Resolver Effectiveness and include the following:

- Studying LinkSource usage and EBSCO A-to-Z reports regularly to discover patterns and problems that need to be fixed;

- Advocating to vendors to fix dissertation target linking;

- Reviewing most frequently used full-text databases for item versus title-level linking, resolving title-level linking to item where possible;

- Examining our ranking order of full-text provider links and making adjustments so that the most reliable databases are offered first;

- Advocating for better management of other electronic resources such as e-books through EBSCO A-to-Z;

- Analyzing the success rate of the top 100 most requested journals using the "Link In by

- Title" usage statistics report in LinkSource and resolving any problems found.

The library benefited from its experience with WebBridge. The knowledge gained was valuable in contributing to the evaluation process and the ultimate decision to move to LinkSource. This year, Belk Library's patrons are experiencing improved access to the library's electronic resources.

The improvements were the result of several concurrent dynamics. The library separated its electronic management from the consortium and is now more flexible and responsive. As part of that separation, the library selected LinkSource as its OpenURL system, which is easy to manage. Industry standards continue to improve. The library has developed better interfaces informed by usability studies.

\section{REFERENCES}

Apps, A., \& Maclntyre, R. (2006). Why OpenURL? D-Lib Magazine, 12(5). doi:10.1045/may2006 apps

Breeding, M. (2012). E-resource knowledge bases and link resolvers: An assessment of the current products and emerging trends. Insights: The UKSG Journal, 25(2), 173-182. doi: 10.1629/2048-

7754.25.2.173 
Culling, J. (2007). Link resolvers and the serials supply chain: Final project report for UKSG. Scholarly Information Strategies. Retrieved from http://www.uksg.org/sites/uksg.org/files/ uksg link resolvers final report.pdf

Glasser, S. (2012). Broken links and failed access. Library Resources \& Technical Services, 56(1), 14-23. Highsmith, A. L., \& Ponsford, B. C. (2011). A resolution in service: SFX usage logs as a basis for link resolver menu redesign. Journal of Web Librarianship, 5(1), 46-62.

doi:10.1080/19322909.2011.544964

Imler, B., \& Eichelberger, M. (2011). Do they "get it"? Student usage of SFX citation linking software.

College \& Research Libraries, 72(5), 454-463.

Livingston, J., Sanford, D., \& Bretthauer, D. (2006). A comparison of OpenURL link resolvers: The results of a University of Connecticut Libraries environmental scan. Library Collections, Acquisitions, and Technical Services, 30(3-4), 179-201.

doi:http://dx.doi.org/10.1016/j.lcats.2006.08.001

O'Neill, L. (2009). Scaffolding OpenURL results: A call for embedded assistance. Internet Reference Services Quarterly, 14(1/2), 13-35. doi:10.1080/10875300902961940

Pesch, O. (2012). Improving OpenURL linking. The Serials Librarian, 63(2), 135-145.

doi:http://dx.doi.org/10.1080/0361526X.2012.689465

Ponsford, B., Stephens, J., \& Sewell, R. R. (2011). Improving OpenURL menus: User testing of

revisions to SFXOR menus. Serials Review, 37(3), 162-170. doi:10.1016/j.serrev.2011.03.016 Stohn, C., Ewing, S., Meares, S., \& Moss, P. (2011). Building and maintaining knowledge bases for OpenURL link resolver-Processes, procedures, and challenges. Against the Grain, 23(1), 26.

Trainor, C., \& Price, J. (2010). Rethinking library linking: Breathing new life Into OpenURL. Chicago: ALA TechSource.

UEPA (User Experience Professionals' Association). (2012). Usability body of knowledge. Retrieved from http://usabilitybok.org/usability-testing

Usability.gov. (2015). Improving the user experience. Retrieved from http://www.usability.gov/ how-toand-tools/methods/recruiting-usability-test-participants.html

\section{APPENDIX A}

\section{Usability Test Script, Notes, and Details}

Users were recruited by approaching likely candidates in the library, with the exception of a few of the faculty, who were asked to meet at the library. Subjects were told the test would take about 10 minutes; the incentive was a $\$ 10$ gift card to the university's bookstore. 


\section{Script for Librarian Conducting the Study}

$\mathrm{Hi} \ldots$ _ my name is__. We appreciate your help with this short usability study. Please know that we're testing our interface, not you, so you can't really do anything wrong.

- What is your class in college (freshman, sophomore)?

- If faculty, what is your department?

Okay, I'm going to ask you to do a specific task using this website. The two titles I'm going to have you search for are on the left monitor. Before we begin, do you have any questions for me?

\section{Instructions for the Librarian Conducting the Study}

Have a word or text document with the title of the articles (we used a desktop with two monitors to make it easier for the participant to copy and paste). Explaining the goal of the study is to see if the participant can find the full text of the article or figure out how to get to full text.

The sword Hrunting in Beowulf: unlocking the word hord

The symbolic meaning of the scabbard decoration of the reich sword

Have the page open to the database International Medieval Bibliography advanced search, and coach the user to copy and paste in the first title. Prompt the subject to use the yellow "find at ASU" button.

When at the "choose affiliation" screen, allow for failure (do not coach through for choosing affiliation). Failure, in this case, is defined as the patron giving up, expressing frustration, or exceeding 2 minutes of searching for the next step.

Next, have the user look for the second title. Repeat the prompts. Note that the second article does not link to full text. At the WebBridge resolution panel, the user could search for journal title (to which we do not have access). The successful solution for the user in this case would be to order the item through Interlibrary Loan without coaching.

After a minute or 2, if the participant is unsuccessful, ask "How would you get help, and/or how would you report an error?" See if anyone goes to the video walkthrough at the top of the page, clicks on the "Ask a librarian" link, or goes to the "Report a problem" link. Encourage the participant to "talk aloud, explain what is confusing." If the participant is "successful" and has moved onto the Interlibrary loan request screen, have him or her return to the WebBridge panel and answer the questions about getting help or reporting a problem.

This test was repeated with LinkSource in place in early 2014. Everything was the same except the WebBridge Resolution panel for the second title was now the LinkSource resolution panel.

Note: If this test was repeated, instead of simply giving the user the title of the article to search, it is recommended that the user see the full citation and have a moment to study it. All users who arrived at the catalog screen showing journal titles were very confused, and it could be they simply had no context. If they had at least seen the title of the journal before searching, it might have helped users

\section{APPENDIX B}




\section{Setup and Maintenance Functionality Comparison Chart}

The functions and features highlighted in light gray are those that worked well for Belk Library's patrons and staff. This table demonstrates that LinkSource was the best choice in this case study.

\begin{tabular}{|c|c|c|}
\hline Functions/Features & WebBridge & LinkSource \\
\hline $\begin{array}{l}\text { Unmediated link to } \\
\text { full text }\end{array}$ & $\begin{array}{l}\text { Called "Direct Connect" in WebBridge. } \\
\text { Flexible in that library can choose which } \\
\text { and how many resources to set up; due to } \\
\text { our consortium environment, the "Choose } \\
\text { Affiliation" menu panel blocked Direct } \\
\text { Connect }\end{array}$ & $\begin{array}{l}\text { Called "direct link to full text" in } \\
\text { LinkSource. All or nothing-works } \\
\text { with smaller vendors. } \\
\text { Interlibrary Loan, works if already } \\
\text { logged on }\end{array}$ \\
\hline Setup & $\begin{array}{l}\text { Challenging-completely manual and library } \\
\text { controlled. Must be set up by library staff }\end{array}$ & $\begin{array}{l}\text { Flexible-vendor and/or library control. } \\
\text { Housed in and connected to the } \\
\text { A-to-Z knowledge base, so resource } \\
\text { links are created automatically }\end{array}$ \\
\hline
\end{tabular}





\begin{tabular}{|c|c|c|}
\hline Functions/Features & WebBridge & LinkSource \\
\hline Technical support & $\begin{array}{l}\text { Challenging and self-help based -Library } \\
\text { staff need thorough, working knowledge } \\
\text { of OpenURL, as Innovative does not } \\
\text { provide tech-support personnel for } \\
\text { WebBridge. There is documentation and a } \\
\text { wiki in CSDirect and a listserv where } \\
\text { customers can share tips. At Belk Library, } \\
\text { we also had the WNCLN network } \\
\text { librarian as a resource. }\end{array}$ & $\begin{array}{l}\text { Helpful and available-EBSCO offers } \\
\text { help pages and tech-support } \\
\text { personnel. More than one person can } \\
\text { open a ticket. No known listserv. }\end{array}$ \\
\hline Admin interface & $\begin{array}{l}\text { Inefficient workflow. Partly this is due to our } \\
\text { consortia setup (WNCLN) and the way it } \\
\text { functions, as we shared the admin interface } \\
\text { with two other institutions. For example, } \\
\text { Resources set "not to show." Staff have to } \\
\text { scroll a long way through the list for all } \\
\text { three schools to find in WebBridge panel } \\
\text { to find status of active or inactive. }\end{array}$ & $\begin{array}{l}\text { Elegant, works well, it is part of Belk } \\
\text { Library's A-to-Z. We do not see the } \\
\text { other school's resources. } \\
\text { For example, Resources set "not to } \\
\text { show." } \\
\text { It is very clear. LinkSource lists the } \\
\text { hidden databases in red at the top of } \\
\text { the interface. }\end{array}$ \\
\hline $\begin{array}{l}\text { Control of the } \\
\text { patron menu }\end{array}$ & $\begin{array}{l}\text { Control of wording: yes } \\
\text { Limited control of look \& feel. Styles } \\
\text { (CSS) access limited. } \\
\text { WNCLN system librarian is the only } \\
\text { person who can make changes. } \\
\text { Cannot load own icons for things like } \\
\text { "interlibrary loan." }\end{array}$ & $\begin{array}{l}\text { Control of wording: yes } \\
\text { Can control, do not have full control } \\
\text { over look and feel. } \\
\text { Any staff member with the log-in } \\
\text { information can change. } \\
\text { Access to CSS is relatively easy. } \\
\text { Can upload local icons. }\end{array}$ \\
\hline Running reports & $\begin{array}{l}\text { Difficult-run for us by the network office, } \\
\text { yet the formatting is unwieldy. }\end{array}$ & $\begin{array}{l}\text { Easy—six kinds of well-formatted } \\
\text { reports can be run in A-to-Z: link in } \\
\text { by source and by metadata format; } \\
\text { link out by title, by category, and by } \\
\text { target. Can filter by IP range. }\end{array}$ \\
\hline $\begin{array}{l}\text { Ranking and } \\
\text { deletion }\end{array}$ & Local control & Local control \\
\hline $\begin{array}{l}\text { Titles set not to } \\
\text { display in A-to-Z }\end{array}$ & $\begin{array}{l}\text { Shows to patron unless manually deleted in } \\
\text { WebBridge coverage files. }\end{array}$ & $\begin{array}{l}\text { Does NOT show up to patron-No } \\
\text { action needed on library's end }\end{array}$ \\
\hline Coverage files & $\begin{array}{l}\text { A monthly task-must be downloaded from } \\
\text { EBSCO's A-to-Z and uploaded to } \\
\text { Innovative's Sierra. }\end{array}$ & $\begin{array}{l}\text { Are automatically synced since } \\
\text { LinkSource is connected to our } \\
\text { A-to-Z selections. }\end{array}$ \\
\hline Data Tests & $\begin{array}{l}\text { Flexible-Can use AND/OR for ISBN, title, } \\
\text { author, etc.; however, due to the technical } \\
\text { level of this function, WNCLN's network } \\
\text { librarian performed these tests or guided } \\
\text { others, which made us key-person } \\
\text { dependent }\end{array}$ & $\begin{array}{l}\text { Less flexible, yet there is tech-support to } \\
\text { help. Not key-person dependent. }\end{array}$ \\
\hline Google Scholar & $\begin{array}{l}\text { Yes, but it was connected to our consortium } \\
\text { "WNCLN" and confusing for patrons. }\end{array}$ & $\begin{array}{l}\text { Yes, moving to LinkSource enabled } \\
\text { ASU to change Google Scholar setup } \\
\text { to search for ASU holdings only, } \\
\text { rather than using the consortium's } \\
\text { setup. This is much less confusing for } \\
\text { the end-user. }\end{array}$ \\
\hline PubMed & $\begin{array}{l}\text { WebBridge menu panel was problematic: the } \\
\text { "Choose Affiliation" wouldn't work; the } \\
\text { PubMed panel developed duplicated lines, } \\
\text { creating a confusing interface. }\end{array}$ & $\begin{array}{l}\text { Yes, EBSCO set this up for us. The } \\
\text { functionality is reliable. The } \\
\text { LinkSource menu is standard. }\end{array}$ \\
\hline
\end{tabular}

